\title{
Versatile Micropatterns of N-Heterocyclic Carbenes on Gold Surfaces: Increased Thermal and Pattern Stability with Enhanced Conductivity
}

\author{
D. Thao Nguyen + Matthias Freitag + , Martin Körsgen, Sebastian Lamping, Andreas Rühling, \\ Andreas H. Schäfer, Martin H. Siekman, Heinrich F. Arlinghaus, Wilfred G. van der Wiel, \\ Frank Glorius, * and Bart Jan Ravoo*
}

\begin{abstract}
Patterned monolayers of $N$-heterocyclic carbenes (NHCs) on gold surfaces were obtained by microcontact printing of $\mathrm{NHC}-\mathrm{CO}_{2}$ adducts and $\mathrm{NHC}(\mathrm{H})\left[\mathrm{HCO}_{3}\right]$ salts. The $\mathrm{NHC}$-modified areas showed an increased conductivity compared to unmodified gold surface areas. Furthermore, the remaining surface areas could be modified with a second, azide-functionalized carbene, facilitating further applications and post-printing modifications. Thorough elucidation by a variety of analytical methods offers comprehensive evidence for the viability of the methodology reported here. The protocol enables facile access to versatile, microstructured NHC-modified gold surfaces with highly stable patterns, enhanced conductivity, and the option for further modification.
\end{abstract}

$N$ Heterocyclic carbenes (NHCs) have unique $\sigma$-electrondonating and $\pi$-accepting properties and are commonly used as electron-rich ligands in transition-metal catalysis. ${ }^{[1]}$ Within the last years, NHCs have proven to be highly valuable ligands on nanoparticles and surfaces. ${ }^{[1-10]}$ In 2011, Weidner et al. discovered that NHCs could serve as ligands on gold surfaces ${ }^{[5]}$ However, gold surfaces with NHCs as ligands are still rarely explored, though a promising future can be envisioned, in which NHCs play a profound role for novel sensors, electronics, and other nanomaterials, many of which utilize gold as a crucial component. ${ }^{[2]}$ Typically, thiols are employed as ligands for gold surfaces. ${ }^{[2,11,12]}$ However, the

[*] D. T. Nguyen, ${ }^{[+]}$M. Freitag, ${ }^{[+]}$S. Lamping, Dr. A. Rühling, Prof. F. Glorius, Prof. B. J. Ravoo

Organisch-Chemisches Institut

Westfälische Wilhelms-Universität Münster

Corrensstrasse 40, 48149 Münster (Germany)

E-mail: glorius@uni-muenster.de

b.j.ravoo@uni-muenster.de

M. Körsgen, Prof. H. F. Arlinghaus

Physikalisches Institut

Westfälische Wilhelms-Universität Münster

Wilhelm-Klemm-Strasse 10, 48149 Münster (Germany)

Dr. A. H. Schäfer

nanoAnalytics $\mathrm{GmbH}$

Heisenbergstrasse 11, 48149 Münster (Germany)

M. H. Siekman, Prof. W. G. van der Wiel

NanoElectronics Group, MESA ${ }^{+}$Institute for Nanotechnology

University of Twente

P.O. Box 217, 7500 AE Enschede (The Netherlands)

$\left.{ }^{+}\right]$These authors contributed equally to this work.

(2) Supporting information and the ORCID identification number(s) for

(DD the author(s) of this article can be found under:

https://doi.org/10.1002/anie.201807197. widespread application of thiols is limited due to a lack of long-term stability even under ambient conditions. ${ }^{[2 c, 12]}$ Therefore, thiol-functionalized surfaces frequently do not display the properties required for modern devices. ${ }^{[2 \mathrm{c}, 12]}$ The Johnson group demonstrated that alkene-substituted NHCs deposited on a gold surface could be further chemically modified with a transition metal catalyst for a ring-opening metathesis polymerization and can be a potential replacement for thiols. ${ }^{[6]}$ Moreover, Crudden et al. demonstrated self-assembled monolayers (SAMs) of NHCs to be exceptionally stable under chemical, oxidative, and physical stress. ${ }^{[7]}$ Recently, Glorius, Fuchs, and co-workers contributed to a deeper understanding of NHC SAMs and NHC mobility on gold. ${ }^{[8]}$ In spite of these insightful findings, to date, metal surfaces have been modified only by immersion techniques or physical-vapor-deposition of carbene- $\mathrm{CO}_{2}$ adducts in ultrahigh vacuum, where the entire gold surface was covered by the NHCs. ${ }^{[2,5-10 b]}$ Considering the versatile nature of NHCs, it would be of broad interest to functionalize gold surfaces with multiple NHCs located in well-defined patterns. ${ }^{[1,2,10]}$ Microcontact printing $(\mu \mathrm{CP})$ is a soft lithography technique to decorate substrates with patterned monolayers. ${ }^{[11,13 a, b, d]}$ The transfer of molecules is commonly ensured by polymeric stamps with a relief pattern, that is, highly ordered micro- or nanostructures.

Herein we report the first successful patterning of NHCs on gold surfaces by $\mu \mathrm{CP}$ with the additional ability to fill the unmodified areas with a second NHC that can be further functionalized (Figure 1).

Crudden et al. have reported that $\mathbf{B I}^{i} \mathbf{P r}$, an analogue of BIMe, forms ultrastable, highly ordered SAMs. ${ }^{[7 a]}$ Bench-

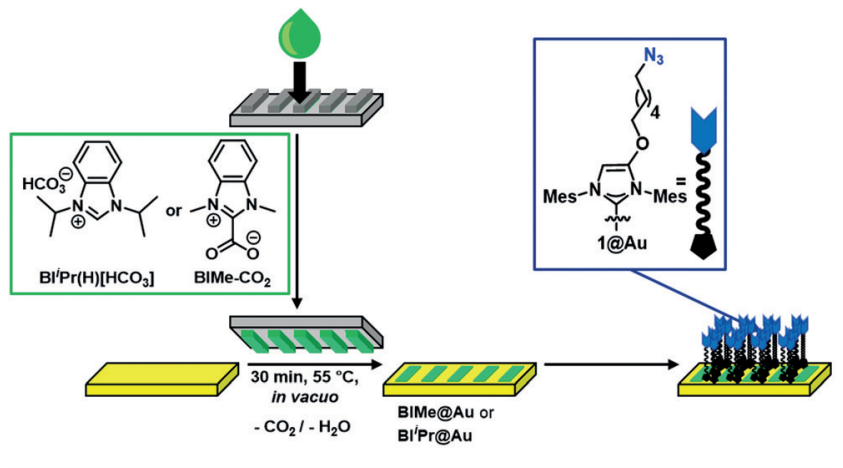

facile procedure $\oplus$ highly stable pattern $\oplus$ enhanced conductivity $\oplus$ selective follow-up chemistry

Figure 1. Procedure for preparing a patterned SAM of NHCs by microcontact printing. 
stable $\mathrm{NHC}-\mathrm{CO}_{2}$ adducts of BIMe or the hydrogen carbonate salt precursor of BI $\mathbf{P}$ r were applied as a clean source of free carbenes instead of imidazolium salt based NHC precursors. ${ }^{[14]}$ Thus, the addition of activating agents (i.e. bases) along with inherent impurities could be avoided. ${ }^{[7 b, 8]}$ In addition, these NHC precursors were found to be compatible with both polar protic solvents and elastomeric stamps used for $\mu \mathrm{CP}$, in contrast to free NHCs. An ozonized PDMS stamp with the desired relief pattern is wetted with an ink solution of BIMe- $\mathrm{CO}_{2}$ in ethanol. The solution is allowed to soak into the elastomeric stamp. Subsequently, the stamp is brought into contact with a gold surface. Heating at $55^{\circ} \mathrm{C}$ in vacuo for 30 min generates the free BIMe under liberation of $\mathrm{CO}_{2} \cdot{ }^{[14]}$ The free NHC is attached to the surface via a covalent bond exclusively at the interface between the bare gold and stamp surface. As a proof of the generality of our printing methodology, $\mu \mathrm{CP}$ was also performed with $\mathbf{B I}^{i} \mathbf{P r}(\mathbf{H})\left[\mathbf{H C O}_{3}\right]$ under optimized printing conditions $\left(55^{\circ} \mathrm{C}\right.$ in vacuo for $\left.30 \mathrm{~min}\right)$. The viability of the herein developed methodology was elucidated by X-ray photoelectron spectroscopy (XPS), time-of-flight secondary ion mass spectrometry (ToF-SIMS), atomic force microscopy (AFM), and scanning electron microscopy (SEM).

The transfer of the NHC to gold was monitored by XPS. The patterning was only successful at temperatures of at least $55^{\circ} \mathrm{C}$, whereas at temperatures of $50^{\circ} \mathrm{C}$ or lower still two bands for the $\mathrm{CO}_{2}$ adduct could be detected in the $\mathrm{C} 1 \mathrm{~s}$ region of the XPS high-resolution spectra (Figure S2). In addition, the emission energy found for the carbene $\mathrm{C}-\mathrm{N}^{*}$ linkage $(400.8 \mathrm{eV})$ in the $\mathrm{N} 1 \mathrm{~s}$ region of the XPS high-resolution spectra (Figure S3) is in excellent agreement with binding energies for NHCs on gold surfaces reported in the literature. ${ }^{[4,7,8]}$ Additionally, no traces of $\mathrm{C}^{*}-\mathrm{O}$ were found in the XPS spectra of printed $\mathbf{B I}^{i} \mathbf{P r}(\mathbf{H})\left[\mathbf{H C O}_{3}\right]$ (Figure S4).

Most modern electronic devices operate at elevated temperatures, for example, processors and solar cells. Therefore, organic molecules deposited on surfaces must ensure a high thermal stability. ${ }^{[10 b, 15]}$ Glorius, Fuchs, and co-workers reported recently that isolated NHCs could perform ballbottype motions in the nanometer regime. ${ }^{[8]}$ Hence, a temperature stress test was applied to assess the overall endurance of the patterns and the persistence of the NHC-gold bond. For this reason, a sample of printed BIMe@Au was subjected to $120^{\circ} \mathrm{C}$ for $16 \mathrm{~h}$. To our delight, the stripes of NHC remained almost unaltered as analyzed by ToF-SIMS, since this method offers high resolution and sensitivity towards all molecular fragments on a surface (Figure 2a,b). ${ }^{[16]}$ This confirms the observation by Glorius, Fuchs, and co-workers that NHCs grouped on a surface remain stationary. ${ }^{[8]}$ High-resolution XPS of the N1s region revealed a retention of BIMe@Au of $94 \%$ (Figure 2c, see the Supporting Information for further details).

The NHC-gold bond is known to be conductive and it was shown that NHCs can reduce the work function of gold by up to $2 \mathrm{eV}$ due to strong electron donation to the metal surface and therefore an increased surface dipole. ${ }^{[6,10 \mathrm{~b}]}$ We carried out conductive probe AFM (CP-AFM) measurements in PeakForce tapping mode (Figure $3 \mathrm{a}, \mathrm{b})$ and observed that areas modified with BIMe and BI'Pr@Au (5 $\mu \mathrm{m}$ stripes, current-to- a

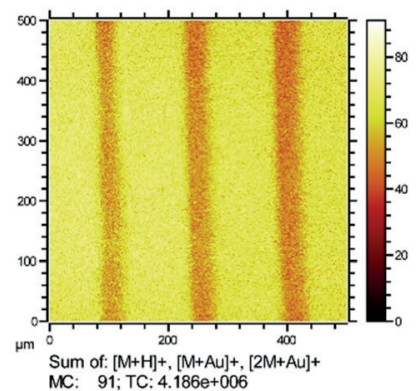

C

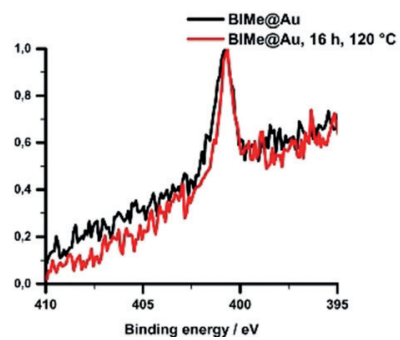

Figure 2. Thermal stress test conducted with BIMe@Au samples (100 $\mu \mathrm{m}$ wide lines spaced by $50 \mu \mathrm{m}$, applied by $\mu \mathrm{CP}$ ). a,b) ToF-SIMS analysis (sum of $[\mathrm{M}+\mathrm{H}]^{+},[\mathrm{M}+\mathrm{Au}]^{+}$and $[2 \mathrm{M}+\mathrm{Au}]^{+}$, field of

view $\left.=500 \times 500 \mu \mathrm{m}^{2}\right)$; a) Sample stored under argon; b) Functionalized surface was subjected to $120^{\circ} \mathrm{C}$ for $16 \mathrm{~h}$. c) High-resolution XPS of the $\mathrm{N} 1 \mathrm{~s}$ region: before stress test (black), after stress test (red).

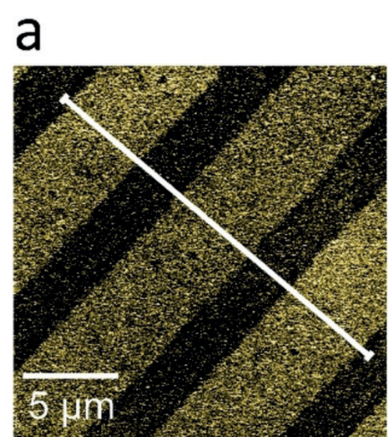

b
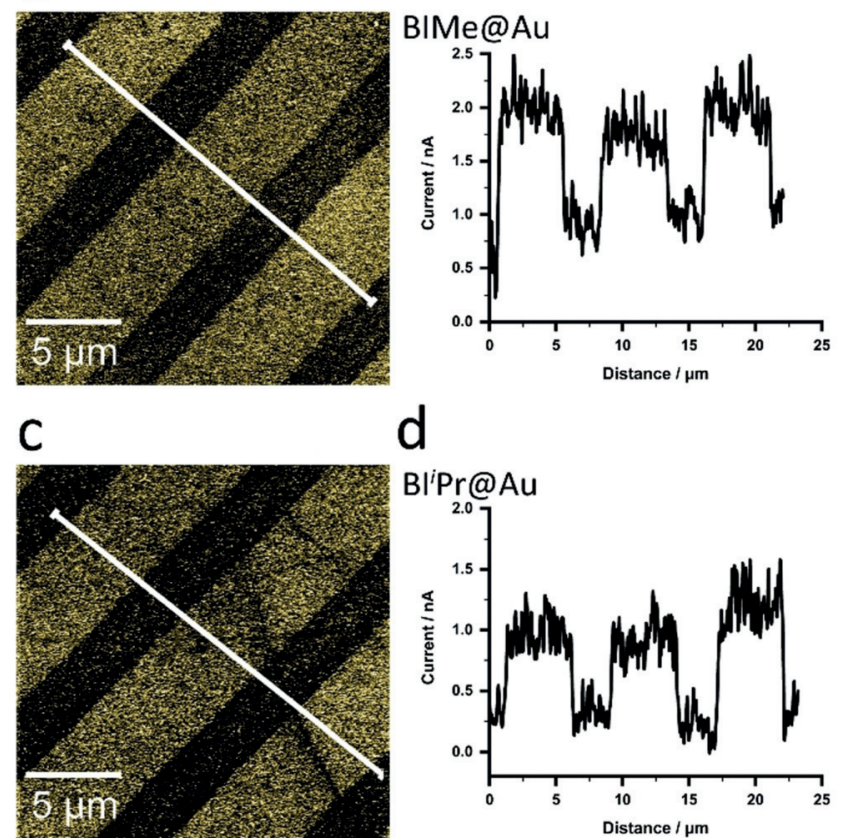

d

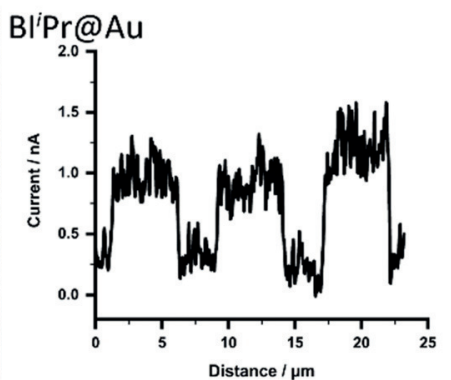

Figure 3. Conducting probe AFM (CP-AFM) measurement of BIMe@Au and BI'Pr@Au (stripes, applied by $\mu C P$ ). a,c) CP-AFM image of the peak current with BIMe and BI'Pr on the broader $5 \mu \mathrm{m}$ stripes, respectively. The white line represents a cross section of the current depending on the location; b,d) The current profile is shown based on the cross section in (a) and (c). 
distance diagram in Figure $3 \mathrm{~b}, \mathrm{~d})$ showed a higher current than undecorated areas ( $3 \mu \mathrm{m}$ stripes), coincident with an increased conductivity of the NHC-decorated surface areas. Although the observed phenomenon could be due to formation of $\mathrm{NHC}_{2} \mathrm{Au}^{0}$ species and subsequent oxidation to $\mathrm{NHC}_{2} \mathrm{Au}^{+}$, induced by the applied voltage from the CP-AFM tip, we note that such charged species have so far been experimentally observed only on nanoparticles. ${ }^{[2 \mathrm{~b}, 3 \mathrm{a}, \mathrm{b}]}$ More likely, the contact resistance of the modified gold surface is reduced as recently reported for gold electrodes of OFET transistors. ${ }^{[7]}$ This would then lead to a reduced contact resistance to the AFM tip and therefore locally resolved higher current at the point where the electric circuit is closed by the AFM tip.

To examine the surface quality after $\mu \mathrm{CP}$, SEM measurements were performed. A highly surface-sensitive upper secondary electron detector was used. BIMe- $\mathbf{C O}_{2}$ was applied by $\mu \mathrm{CP}(100 \mu \mathrm{m}$ wide lines $50 \mu \mathrm{m}$ apart $)$ and the interspaces were filled with 1-octadecanethiol from solution. Bright areas represent the NHC-modified surface. The increased brightness can be attributed to a higher secondary electron yield due to a more electron-rich gold surface compared to the thiol-modified area (Figure S32).

IMes- $\mathbf{C O}_{2}$ was also used for $\mu \mathrm{CP}$ to compare it directly to its $\mathrm{HBr}$ salt counterpart. The transfer of IMes- $\mathbf{C O}_{2}$ was confirmed by XPS and ToF-SIMS (Figures S5 and S23). ${ }^{[7,8]}$ $\mu \mathrm{CP}$ was then repeated with IMes-HBr to show that the methodology would not be applicable to the salt analogue. IMes.HBr could not be detected by XPS after the obligatory washing step (Figure S8). It can be concluded that a covalent bond between NHC and Au was only obtained by using the $\mathrm{CO}_{2}$ adducts or the $\mathrm{HCO}_{3}{ }^{-}$salts.

To expand the versatility of the patterning, non-utilized surfaces were decorated orthogonally with alternative surface modifiers, such as a second NHC from solution. Newly designed NHC precursors $\mathbf{1}$ (azide in the backbone) or $\mathbf{2}$ (azide on the $N$-substituted side chains) were applied as salts from solution by in situ deprotonation (Figure 4). The functionalization with azide-functionalized NHCs offered the opportunity for copper-catalyzed azide-alkyne cycloaddition (CuAAC). ${ }^{[13]}$

The formation of triazene adducts is a serious concern when discussing azide moieties in conjunction with NHCs. ${ }^{[2 a, 17]}$ Accordingly, NHCs modified with azides could suffer from undesired intermolecular coupling or step-growth polymerization reactions. To obtain more insight, whether coupling of $\mathbf{1}$ in solution occurs, $\mathrm{KO}^{t} \mathrm{Bu}$ (1.2 equiv) in $\left[\mathrm{D}_{8}\right] \mathrm{THF}$ was added to a $10 \mathrm{~mm}$ solution of $\mathbf{1 ( N 3 ) \cdot H B r}$ in $\left[\mathrm{D}_{8}\right]$ THF. After a reaction time of $1 \mathrm{~h}$, the solution was analyzed by NMR and HRMS. A new peak at 215.9 ppm in the ${ }^{13} \mathrm{C}$ NMR spectrum can be attributed to the carbene carbon, while the peak for the $\mathrm{C} 2$ proton of the imidazole ring at $10.94 \mathrm{ppm}$ has vanished. Moreover, the ${ }^{1} \mathrm{H}$ NMR signals for the $\mathrm{C} 5$ proton of the imidazole ring and the $\mathrm{OCH}_{2}$ protons are shifted upfield in case of the carbene, while the $\mathrm{N}_{3} \mathrm{CH}_{2}$ peak is not shifted. After quenching of the solution, no mass peaks could be attributed to coupling products of $\mathbf{1}$, but protonated $\mathbf{1}$ can be clearly detected (see the Supporting Information for further details and discussion). Neither technique gave
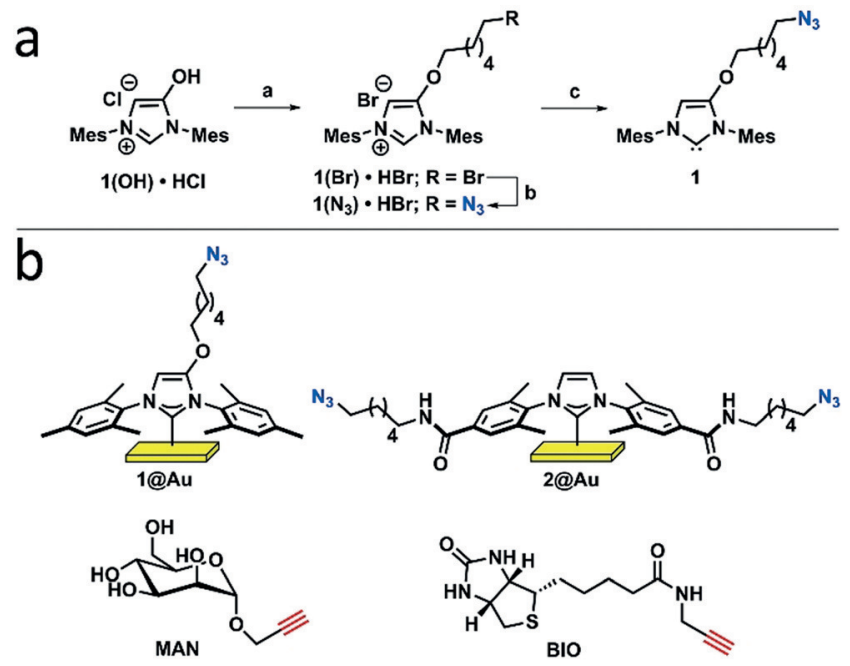

Figure 4. a) Synthesis of IMes derivative 1. a) 1. $\mathrm{NEt}_{3}$ (1.1 equiv), $\mathrm{CH}_{2} \mathrm{Cl}_{2}(0.1 \mathrm{M}), 0.5 \mathrm{~h}, \mathrm{RT}$; 2. removal of $\mathrm{CH}_{2} \mathrm{Cl}_{2}$, EtOAc (0.04 M), Ar; 3. $\mathrm{BrCH}_{2}\left(\mathrm{CH}_{2}\right)_{4} \mathrm{CH}_{2} \mathrm{Br}$ (3 equiv), $60^{\circ} \mathrm{C}, 16 \mathrm{~h}$; b) $\mathrm{NaN}_{3}$ (1.2 equiv), DMF $(0.04 \mathrm{M}), 60^{\circ} \mathrm{C}, 4 \mathrm{~h}$; c) KO ${ }^{t} \mathrm{Bu}$ (1.2 equiv), THF (0.01 M), RT. b) IMes derivatives $\mathbf{1}$ and $\mathbf{2}$ are taken to react with either MAN or BIO in a CuAAC.

evidence for triazene formation in solution. We further analyzed a gold surface modified with a drop of a $10 \mathrm{~mm}$ solution of 1 by XPS. The peaks at $399.8 \mathrm{eV}$ and $404.7 \mathrm{eV}$ in the $\mathrm{N} 1 \mathrm{~s}$ region can be attributed to the azide group and a peak at $400.9 \mathrm{eV}$ indicates the formation of a covalent carbene-gold bond (Figure S9).

With this knowledge in hand, we immersed the gold substrates patterned with BIMe@Au in a solution of in situ generated free carbenes $\mathbf{1}$ or $\mathbf{2}$. The resulting XPS spectra showed bands for the azide head group in the $\mathrm{N} 1 \mathrm{~s}$ region for both NHC 1 and NHC 2 (Figures S14, S17 and S20). Due to the low intensity of the azide band, we additionally conducted attenuated total reflection infrared spectroscopy (ATR-IR) of the surface modified with NHC 1 for further support of the XPS data, and a band corresponding to the azide group was found at $2086 \mathrm{~cm}^{-1}$ (Figure S33).

Finally, mannose (MAN) and biotin (BIO) with a terminal alkyne moiety were taken as substrates for CuAAC, as these molecules are well known and established for protein recognition. ${ }^{[13 \mathrm{~b}, \mathrm{c}]}$ The results of the CuAAC are 1MAN@Au, 2-MAN@Au, and 1-BIO@Au. The XPS spectrum was then recorded after each of the various chemical modification steps (Figures S13-S21). Furthermore, ToFSIMS was applied to visualize the patterning of the NHC SAMs. As an example, Figure 5a,b depicts the high-resolution XPS spectra of BIMe@Au and 1-MAN@Au. The final azide-alkyne cycloaddition resulting in 1-MAN@Au resulted in peaks characteristic for triazole in the N1s spectra and a vanished azide band (Figure $5 \mathrm{a}$ ). ${ }^{[13 \mathrm{e}]}$

In the $\mathrm{C} 1 \mathrm{~s}$ region, a distinct shoulder to a higher binding energy could be observed, which can be attributed to numerous $\mathrm{C}-\mathrm{O}$ bonds in mannose. The ToF-SIMS mapping showed characteristic molecular fragment signals for BIMe@Au as dots with the right dimensions and even the nonfragmented molecule could be observed as gold adduct 
a

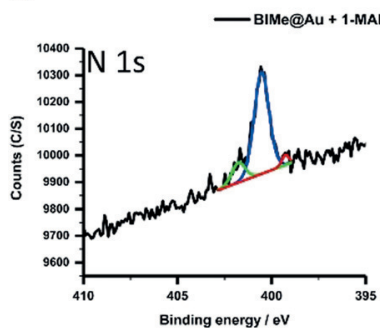

C

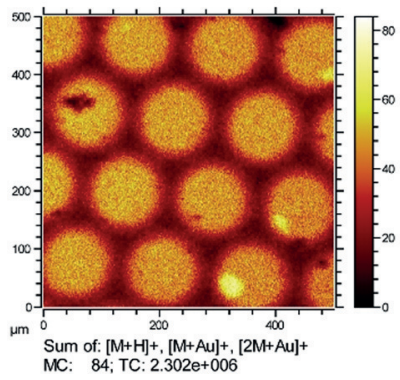

b

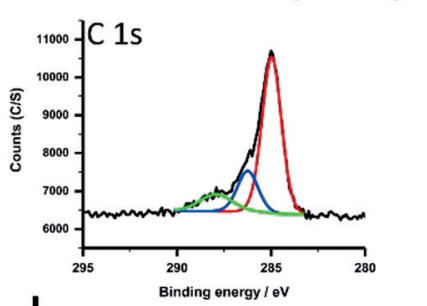

d

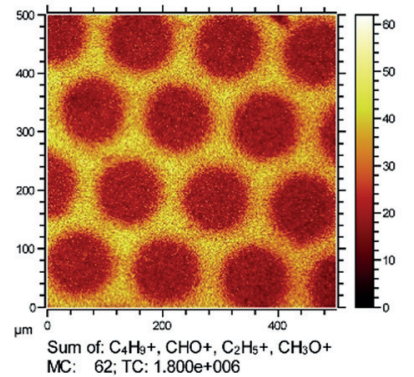

Figure 5. Samples with BIMe@Au and 1-MAN@Au. Final XPS spectra: a) $\mathrm{N} 1 \mathrm{~s}$ region with triazole (red, green) and $\mathrm{C}-\mathrm{N} *$ (blue) peak. b) $\mathrm{C} 1 \mathrm{~s}$ region with $\mathrm{C}^{*}-\mathrm{C}$ (red), $\mathrm{C} *-\mathrm{N}$ (blue), and $\mathrm{C} *-\mathrm{O}$ (green) peak. c) ToFSIMS analysis of BIMe@Au (sum of $[\mathrm{M}+\mathrm{H}]^{+},[\mathrm{M}+\mathrm{Au}]^{+}$and $[2 \mathrm{M}+\mathrm{Au}]^{+}$, field of view $\left.\left.=500 \times 500 \mu \mathrm{m}^{2}\right) ; \mathrm{d}\right)$ ToF-SIMS analysis of 1-MAN@Au (sum of $\mathrm{C}_{4} \mathrm{H}_{9}{ }^{+}, \mathrm{CHO}^{+}, \mathrm{C}_{2} \mathrm{H}_{5}{ }^{+}$and $\mathrm{CH}_{2} \mathrm{O}^{+}$, field of view $\left.=500 \times 500 \mu \mathrm{m}^{2}\right)$ BIMe- $\mathrm{CO}_{2}$ printed as dots $(100 \mu \mathrm{m}$ spaced by $50 \mu \mathrm{m})$ and 1 was used to fill up all unmodified areas. CuAAC facilitated the addition of MAN

(Figure 5c). To our delight, the sharp edges of the patterns remained unchanged over the whole process and characteristic mannose fragments could only be detected in the interspaces, which indicates a predominant modification of NHC 1 with a homogeneous coverage (Figure $5 \mathrm{~d}$ ). More analytical data regarding post-printing chemical modification can be found in the Supporting Information.

As a proof of functionality, protein recognition tests of mannose-terminated 1-MAN@Au with lectin concanavalin A (ConA) were performed. ${ }^{[13 \mathrm{~b}]}$ Although gold is known to quench fluorescent light at close distances, weak but significant fluorescence for 1-MAN@Au with ConA could be detected in the mannose-functionalized region (Figure S4 e). ${ }^{[18]}$

In summary we have introduced a new and straightforward approach for the well-ordered and micropatterned functionalization of gold surfaces with NHCs, utilizing the robustness of $\mu \mathrm{CP}$ and subsequent orthogonal modifications with a second NHC from solution while retaining an excellent spatial separation of the two NHCs. Once the NHCs were applied to gold, it was found that the patterning could withstand exposure to high temperatures for at least $16 \mathrm{~h}$. Our method was validated by detailed XPS, TOF-SIMS, and SEM analysis. CP-AFM measurements could depict a locally increased conductivity for areas modified with the NHCs. Due to the functional groups on the employed NHCs, it was possible to functionalize the gold surface after $\mu \mathrm{CP}$ by $\mathrm{CuAAC}$, such as with mannose or biotin labels for protein recognition. In view of the unique properties of NHCs,

surface micropatterning opens the door to a wide range of applications in sensing and nanoelectronics that benefit from the strong and robust NHC anchors on the surface and their impact on the metal electronics. Deeper investigation regarding the surface electronics are currently ongoing.

\section{Acknowledgements}

Generous funding from the Deutsche Forschungsgemeinschaft (SFB 858 and Leibniz award) is gratefully acknowledged. We thank Johannes B. Ernst and Ute Allebrod for experimental support. We are grateful to the MEET for providing the facility to sputter the Au surfaces. Martin Bühner (nanoAnalytics $\mathrm{GmbH}$ ) is acknowledged for SEM analysis. We thank Deb Kumar Bhowmick for IR measurements and Andreas Lerchen for helpful discussions.

\section{Conflict of interest}

The authors declare no conflict of interest.

Keywords: gold surfaces - microcontact printing · $\mathrm{N}$-heterocyclic carbenes · self-assembled monolayers

How to cite: Angew. Chem. Int. Ed. 2018, 57, 11465-11469 Angew. Chem. 2018, 130, 11637-11641

[1] a) M. N. Hopkinson, C. Richter, M. Schedler, F. Glorius, Nature 2014, 510, 485; b) S. P. Nolan, C. S. J. Cazin, Science of Synthesis: $\mathrm{N}$-Heterocyclic Carbenes in Catalytic Organic Synthesis, Vol. 1 (Eds.: S. P. Nolan, C. S. J. Cazin), Georg Thieme, Stuttgart, 2017.

[2] a) A. V. Zhukhovitskiy, M. J. MacLeod, J. A. Johnson, Chem. Rev. 2015, 115, 11503; b) S. Roland, X. Ling, M.-P. Pileni, Langmuir 2016, 32, 7683; c) S. Engel, E. Fritz, B. J. Ravoo, Chem. Soc. Rev. 2017, 46, 2057.

[3] a) E. C. Hurst, K. Wilson, I. J. S. Fairlamb, V. Chechik, New J. Chem. 2009, 33, 1837; b) J. Vignolle, T. D. Tilley, Chem. Commun. 2009, 7230; c) K. V. S. Ranganath, J. Kloesges, A. H. Schäfer, F. Glorius, Angew. Chem. Int. Ed. 2010, 49, 7786; Angew. Chem. 2010, 122, 7952; d) K. V. S. Ranganath, A. Schäfer, F. Glorius, Chem CatChem 2011, 3, 1889; e) J. B. Ernst, S. Muratsugu, F. Wang, M. Tada, F. Glorius, J. Am. Chem. Soc. 2016, 138, 10718; f) L. M. Martínez-Prieto, A. Ferry, L. Rakers, C. Richter, P. Lecante, K. Philippot, B. Chaudret, F. Glorius, Chem. Commun. 2016, 52, 4768; g) J. B. Ernst, C. Schwermann, G. Yokota, M. Tada, S. Muratsugu, N. L. Doltsinis, F. Glorius, J. Am. Chem. Soc. 2017, 139, 9144.

[4] a) P. Lara, O. Rivada-Wheelaghan, S. Conejero, R. Poteau, K. Philippot, B. Chaudret, Angew. Chem. Int. Ed. 2011, 50, 12080; Angew. Chem. 2011, 123, 12286; b) E. A. Baquero, S. Tricard, J. C. Flores, E. de Jesús, B. Chaudret, Angew. Chem. Int. Ed. 2014, 53, 13220; Angew. Chem. 2014, 126, 13436; c) A. Rühling, K. Schaepe, L. Rakers, B. Vonhören, P. Tegeder, B. J. Ravoo, F. Glorius, Angew. Chem. Int. Ed. 2016, 55, 5856; Angew. Chem. 2016, 128, 5950; d) N. Möller, A. Rühling, S. Lamping, T. Hellwig, C. Fallnich, B. J. Ravoo, F. Glorius, Angew. Chem. Int. Ed. 2017, 56, 4356; Angew. Chem. 2017, 129, 4421; e) K. Salorinne, R. W. Y. Man, C.-H. Li, M. Taki, M. Nambo, C. M. Crudden, Angew. Chem. Int. Ed. 2017, 56, 6198; Angew. Chem. 2017, 129, 6294. 
[5] T. Weidner, J. E. Baio, A. Mundstock, C. Große, S. Karthäuser, C. Bruhn, U. Siemeling, Aust. J. Chem. 2011, 64, 1177.

[6] A. V. Zhukhovitskiy, M. G. Mavros, T. Van Voorhis, J. A Johnson, J. Am. Chem. Soc. 2013, 135, 7418.

[7] a) C. M. Crudden, J. H. Horton, I. I. Ebralidze, O. V. Zenkina, A. B. McLean, B. Drevniok, Z. She, H.-B. Kraatz, N. J. Mosey, T. Seki, E. C. Keske, J. D. Leake, A. Rousina-Webb, G. Wu, Nat. Chem. 2014, 6, 409; b) C. M. Crudden, J. H. Horton, M. R. Narouz, Z. Li, C. A. Smith, K. Munro, C. J. Baddeley, C. R. Larrea, B. Drevniok, B. Thanabalasingam, A. B. McLean, O. V. Zenkina, I. I. Ebralidze, Z. She, H.-B. Kraatz, N. J. Mosey, L. N Saunders, A. Yagi, Nat. Commun. 2016, 7, 12654; c) A. Lv, M. Freitag, K. M. Chepiga, A. H. Schäfer, F. Glorius, L. Chi, Angew. Chem. Int. Ed. 2018, 57, 4792; Angew. Chem. 2018, 130, 4883.

[8] G. Wang, A. Rühling, S. Amirjalayer, M. Knor, J. B. Ernst, C. Richter, H.-J. Gao, A. Timmer, H. Gao, N. L. Doltsinis, F. Glorius, H. Fuchs, Nat. Chem. 2017, 9, 152.

[9] C.-Y. Wu, W. J. Wolf, Y. Levartovsky, H. a. Bechtel, M. C. Martin, F. D. Toste, E. Gross, Nature 2017, 541, 511.

[10] a) R. Zhong, A. C. Lindhorst, F. J. Groche, F. E. Kühn, Chem. Rev. 2017, 117, 1970; b) H. K. Kim, A. S. Hyla, P. Winget, H. Li, C. M. Wyss, A. J. Jordan, F. A. Larrain, J. P. Sadighi, C. FuentesHernandez, B. Kippelen, J.-L. Brédas, S. Barlow, S. R. Marder, Chem. Mater. 2017, 29, 3403.

[11] a) A. Kumar, G. M. Whitesides, Appl. Phys. Lett. 1993, 63, 2002; b) Y. Xia, G. M. Whitesides, Langmuir 1997, 13, 2059; c) J. C. Love, L. A. Estroff, J. K. Kriebel, R. G. Nuzzo, G. M. Whitesides, Chem. Rev. 2005, 105, 1103; d) A. Perl, D. N. Reinhoudt, J. Huskens, Adv. Mater. 2009, 21, 2257; e) D. Qin, Y. Xia, G. M. Whitesides, Nat. Protoc. 2010, 5, 491.

[12] a) C. Vericat, M. E. Vela, G. Benitez, P. Carro, R. C. Salvarezza, Chem. Soc. Rev. 2010, 39, 1805; b) J. B. Schlenoff, M. Li, H. Ly, J.
Am. Chem. Soc. 1995, 117, 12528; c) M. H. Schoenfisch, J. E. Pemberton, J. Am. Chem. Soc. 1998, 120, 4502.

[13] a) T. Kaufmann, B. J. Ravoo, Polym. Chem. 2010, 1, 371; b) C. Wendeln, S. Rinnen, C. Schulz, T. Kaufmann, H. F. Arlinghaus, B. J. Ravoo, Chem. Eur. J. 2012, 18, 5880; c) G. V. Dubacheva, C. Araya-Callis, A. Geert Volbeda, M. Fairhead, J. Codée, M. Howarth, R. P. Richter, J. Am. Chem. Soc. 2017, 139, 4157; d) J. E. Hein, V. V. Fokin, Chem. Soc. Rev. 2010, 39, 1302; e) S. Ciampi, T. Böcking, K. A. Kilian, M. James, J. B. Harper, J. J. Gooding, Langmuir 2007, 23, 9320.

[14] a) A. M. Voutchkova, M. Feliz, E. Clot, O. Eisenstein, R. H. Crabtree, J. Am. Chem. Soc. 2007, 129, 12834; b) L. J. Murphy, K. N. Robertson, R. Kemp, H. M. Tuononen, J. a. C. Clyburne, Chem. Commun. 2015, 51, 3942.

[15] a) B. A. C. Dürr, F. Schreiber, M. Kelsch, H. D. Carstanjen, H. Dosch, Adv. Mater. 2002, 14, 961; b) B. C. Thompson, J. M. J. Fréchet, Angew. Chem. Int. Ed. 2008, 47, 58; Angew. Chem. 2008, 120,62 .

[16] a) A. Benninghoven, Angew. Chem. Int. Ed. Engl. 1994, 33, 1023; Angew. Chem. 1994, 106, 1075; b) F. Draude, M. Körsgen, A. Pelster, T. Schwerdtle, J. Müzhing, H. F. Arlinghaus, Anal. Bioanal. Chem. 2015, 407, 2203.

[17] D. J. Coady, D. M. Khramov, B. C. Norris, A. G. Tennyson, C. W. Bielawski, Angew. Chem. Int. Ed. 2009, 48, 5187; Angew. Chem. 2009, 121, 5289 .

[18] B. Dubertret, M. Calame, A. J. Libchaber, Nat. Biotechnol. 2001, 19,365 .

Manuscript received: January 19, 2018

Revised manuscript received: June 22, 2018

Accepted manuscript online: June 28, 2018

Version of record online: July 26, 2018 